\title{
PENINGKATAN KINERJA GURU MELALUI SUPERVISI PENGAWAS SATUAN PENDIDIKAN DAN KEPEMIMPINAN KEPALA SEKOLAH (STUDI KASUS PADA SMA MA'ARIF NU 5 PURBOLINGGO KABUPATEN LAMPUNG TIMUR)
}

\author{
Dwi Rohmadi Mustofa, Ide Lia Marzuki,Ihsan Mustofa \\ Jl. Raya Wonokriyo Gadingrejo Pringsewu \\ Email: stitpringsewu @ gmail.com
}

\begin{abstract}
The purpose of this study was to determine; (1) positive influence and significant correlation between the regulatory supervision of the educational unit on teacher performance of the SMA Maarif NU 5 Purbolinggo, East Lampung regency; (2) positive influence and significant correlation between school leadership on teacher performance; (3) positive and significant influence between the regulatory supervision of the education unit and school leadership together on teacher performance.

Population or census, the permanent teachers in high school Maarif NU 5 Purbolinggo totaling 36 people. Primary data was collected by a questionnaire instrument. Data were analyzed qualitatively and quantitatively with the correlation formula, linear regression and multiple linear regression.

The results showed; (1) a significant difference supervisors supervising teacher education unit on the performance of the SMA Maarif NU 5 Purbolinggo, East Lampung regency; (2) there is a significant impact of school leadership on teacher performance; (3) there is a significant influence supervision unit superintendent of education and school leadership together on teacher performance.
\end{abstract}

\begin{abstract}
Abstrak
Tujuan penelitian ini adalah untuk mengetahui; (1) Pengaruh yang positif dan signifikan antara supervisi pengawas satuan pendidikan terhadap kinerja guru pada SMA Ma'arif NU 5 Purbolinggo, Kabupaten Lampung Timur; (2) Pengaruh yang positif dan signifikan antara kepemimpinan kepala sekolah terhadap kinerja guru; (3) Pengaruh yang positif dan signifikan antara supervisi pengawas satuan pendidikan dan kepemimpinan kepala sekolah secara bersama-sama terhadap kinerja guru.

Populasi penelitian terhadap guru tetap di SMA Ma'arif NU 5 Purbolinggo berjumlah 36 orang. Data primer dikumpulkan dengan instrumen kuesioner. Data dianalisis secara kualitatif dan kuantitatif dengan rumus korelasi, regresi linier, dan regresi linier berganda.

Hasil penelitian menunjukkan; (1) terdapat pengaruh yang signifikan supervisi pengawas satuan pendidikan terhadap kinerja guru pada SMA Ma'arif NU 5 Purbolinggo, Kabupaten Lampung Timur; (2) terdapat pengaruh yang signifikan kepemimpinan kepala sekolah terhadap kinerja guru; (3) terdapat pengaruh yang signifikan supervisi pengawas satuan pendidikan dan kepemimpinan kepala sekolah secara bersama-sama terhadap kinerja guru.
\end{abstract}

Kata kunci: supervisi pengawas, kepemimpinan, kinerja guru, SMA Ma'arif $N U$ 


\section{A. PENDAHULUAN}

Di tengah arus perubahan dan perkembangan teknologi dan ekonomi, profesi guru dituntut untuk terus meningkatkan profesionalismenya. Guru dan tenaga kependidikan mempunyai peran sebagai faktor penentu keberhasilan tujuan pendidikan. Hal ini karena guru langsung berinteraksi dengan peserta didik untuk memberikan bimbingan, arahan, fasilitasi pembelajaran, yang muaranya menghasilkan lulusan lembaga pendidikan yang sesuai dengan tujuan pendidikan. Salah satu aspek profesionalisme guru itu adalah adanya peningkatan kinerja guru.

Usman (2005:85) menyatakan bahwa pekerjaan profesional dituntut: (1) memiliki kode etik, sebagai acuan dalam melaksanakan tugas dan fungsinya; (2) memiliki klien/obyek layanan yang tetap, seperti dokter dengan pasiennya, guru dengan muridnya; (3) diakui oleh masyarakat karena memang diperlukan jasanya di masyarakat. Suatu pekerjaan profesional memerlukan persyaratan khusus, yakni (1) menuntut adanya keterampilan berdasarkan konsep dan teori ilmu pengetahuan yang mendalam; (2) menekankan pada suatu keahlian dalam bidang tertentu sesuai dengan bidang profesinya; (3) menuntut adanya tingkat pendidikan yang memadai; (4) adanya kepekaan terhadap dampak kemasyarakatan dari pekerjaan yang dilaksanakannya; (5) memungkinkan sejalan dengan dinamika kehidupan.

Nawawi (2003:243) menyatakan standar pekerjaan adalah sejumlah ukuran dalam penilaian karya, yang dipergunakan sebagai pembanding cara dan hasil pelaksanaan tugastugas dari suatu pekerjaan/jabatan.

Peran profesi guru memiliki predikat profesional. Istilah kinerja dalam penelitian ini lebih mengarah kepada: (1). Prestasi kerja, (2). Ketaatan, (3). Tanggung jawab, (4). Kerjasama, dan (5). Prakarsa guru dalam melaksanakan kegiatan pembelajaran di sekolah.

Upaya-upaya untuk meningkatkan kinerja itu dapat dilakukan dengan cara mengadakan supervisi, memberikan motivasi, memberikan insentif, memberikan kesempatan untuk mengembangkan karir, meningkatkan kemampuan, penyediaan sumber dan sarana belajar, dan praktik kepemimpinan yang baik. Sementara kinerja guru dapat ditingkatkan apabila yang bersangkutan mengetahui apa yang diharapkan dan kapan bisa menetapkan harapan-harapan yang diakui hasil kerjanya.

Guru merupakan ujung tombak dari setiap kebijakan atau yang berkaitan dengan pendidikan, karena gurulah yang akan melaksanakan secara operasional segala bentuk pola gerak perubahan kurikulum.
Pengembangan sumber daya guru wajib dilakukan untuk mencapai tujuan pendidikan nasional secara menyeluruh. Kinerja guru yang rendah akan berdampak pada rendahnya mutu pendidikan. Kinerja guru dapat diukur dari kinerja dalam mendesain program pembelajaran dan kinerja dalam melaksanakan proses pembelajaran. Kinerja seorang guru dipengaruhi antara lain oleh faktor pembinaan, inisiatif, tanggung jawab, minat terhadap tugas, penghargaan terhadap tugas, dan komunikasi.

Berkaitan dengan konsep quality assurance atau penjaminan mutu pendidikan, Peraturan Pemerintah Nomor 19 Tahun 2005 tentang Standar Mutu Pendidikan menegaskan bahwa peranan pengawas satuan pendidikan/sekolah sangat penting pada satuan pendidikan binaannya. Oleh sebab itu pembinaan pengawas satuan pendidikan mutlak diperlukan sebagai pelaksanaan tugas kepengawasan akademik dan manajerial melalui pemantauan, penilaian, pembinaan, pelaporan, dan tindak lanjut.

Pengawas pembina bersama kepala sekolah harus terus berupaya untuk meningkatkan mutu pembelajaran di sekolah. Fokus pembinaan guru oleh pengawas sekolah adalah Standar Isi (Permendiknas Nomor 22 Tahun 2006), Standar Kompetensi Lulusan (Permendiknas Nomor 23 Tahun 2006), Standar Proses (Permendiknas Nomor 41 Tahun 2007), Standar Penilaian (Permendiknas Nomor 20 Tahun 2007) yang apabila dilaksanakan dengan komitmen, konsisten, dan konsekuen yang tinggi, maka akan terjadi perubahan mutu pembelajaran yang signifikan.

Keberhasilan pencapaian tujuan pendidikan sangat ditentukan oleh peran guru. Hal ini dapat diterima, sebab guru merupakan pemegang kendali utama dalam pelaksanaan pendidikan. Guru dengan segala karakteristiknya merupakan faktor penentu utama dalam menyusun rencana yang pada gilirannya sangat menentukan keefektifan pembelajaran. Tampaknya tidak berlebihan jika persoalan menurunnya mutu hasil pendidikan di Indonesia ini sorotan utama terarah pada kinerja guru sebagai pemegang kendali.

Upaya-upaya untuk meningkatkan mutu pendidikan disadari satu kebenaran fundamental, yakni bahwa kunci keberhasilan mempersiapkan dan menciptakan guru-guru yang profesional yang memiliki kekuatan tanggungjawab yang baru untuk merencanakan pendidikan di masa depan.

Guru harus mengembangkan keprofesionalan secara berkelanjutan dan melakukan tindakan reflektif. Hal ini menunjukkan bahwa seorang guru profesional harus terampil dalam melaksanakan tugas pembelajaran dan terus menerus melakukan 
upaya peningkatan kinerja. Peningkatan kinerja guru tidak saja menjadi tanggung jawab guru, tetapi juga kepala sekolah dan pengawas satuan pendidikan.

Peraturan Menteri Pendidikan Nasional Nomor 12 tahun 2007 tentang Standar Kualifikasi dan Kompetensi Pengawas, menegaskan ada enam dimensi kompetensi pengawas satuan pendidikan yang telah disahkan oleh BSNP. Keenam dimensi kompetensi tersebut adalah kompetensi kepribadian, kompetensi social, kompetensi supervisi manajerial, kompetensi supervisi akademik, kompetensi evaluasi pendidikan dan kompetensi penelitian pengembangan.

Istilah supervisi mengandung beberapa aspek penting yaitu: (a) bersifat bantuan dan pelayanan kepada kepala sekolah, guru dan staf; (b) untuk mengembangkan mutu guru; (c) untuk mengembangkan profesional guru; dan (d) untuk memotivasi guru (Masaong, 2012:3). Aspek-aspek tersebut menuntut pengetahuan tentang konsep-konsep dan pendekatan supervisi yang ditunjang dengan kinerja serta akuntabilitas yang tinggi dari supervisor. Hal ini dimaksudkan agar kegiatan supervisi sebagai layanan profesional dapat meningkatkan kompetensi guru dalam pembelajaran yang bermuara pada hasil belajar peserta didik secara optimal.

Peran supervisi pengawas sebagai pembina dan pembimbing mempunyai manfaat ganda. Pengawas tidak hanya berperan sebagai resources person atau konsultan, bahkan secara kolaboratif dapat bersama-sama dengan guru melakukan peningkatan pembelajaran.

Berdasarkan pengamatan sementara diperoleh data tentang kurangnya pembinaan dari pengawas, lemahnya kepemimpinan kepala sekolah, kurangnya sarana dan prasarana penunjang pembelajaran di sekolah, dan rendahnya minat guru untuk mengembangkan potensi dirinya. Melihat kenyataan di atas dirasa perlu dilakukan peningkatan pembinaan oleh pengawas satuan pendidikan dan praktik kepemimpinan kepala sekolah sesuai dengan situasi dan kondisi sekolah.

\section{METODE PENELITIAN}

\section{Jenis Penelitian}

Penelitian ini termasuk dalam penelitian kuantitatif, menggunakan metode survey. Analisis penelitian menggunakan analisis kontribusi menggunakan korelasi $\left(\mathrm{R}_{\text {Square }}\right)$.

2. Data Penelitian dan Teknik Analisis Data

Populasi dalam penelitian ini meliputi seluruh guru tetap di SMA Ma'arif NU 5 Purbolinggo, Kabupaten Lampung Timur berjumlah 36 orang. Teknik pengumpulan data dengan cara wawancara, kuesioner, dan dokumentasi.
Data dianalisis secara kualitatif dengan teknik persentase dan kuantitatif dengan rumor korelasi, regresi linier, Uji-F dan Uji-t.

\section{HASIL DAN PEMBAHASAN}

\section{Analisis Data}

\section{A. Analisis Supervisi PSP}

Tabel 1.Distribusi Data Skor Supervisi Pengawas Satuan Pendidikan

\begin{tabular}{|c|l|l|c|c|}
\hline No & Skor & Kategori & Frekuensi & \% \\
\hline 1 & $22-$ & Baik & 4 & 11,11 \\
& 24 & & & \\
\hline 2 & $19-$ & Cukup & 22 & 61,11 \\
& $21-$ & Baik & & \\
\hline 3 & $16-$ & Kurang & 10 & 27,77 \\
& 18 & Baik & & \\
\hline & & Jumlah & $\mathbf{3 6}$ & $\mathbf{1 0 0}$ \\
\hline
\end{tabular}

Sumber: Data Primer Diolah, 2016

Dari 36 responden penelitian, yang menyatakan bahwa pelaksanaan supervisi pengawas satuan pendidikan telah dilaksanakan dengan Baik dinyatakan oleh 4 responden $(11,11 \%)$, yang menyatakan Cukup Baik ada 22 responden $(61,11 \%)$ yang menyatakan Kurang Baik ada 10 responden $(27,77 \%)$. Dari hasil di atas, dominannya jawaban responden yang menyatakan bahwa supervisi pengawas satuan pendidikan termasuk dalam kategori Cukup Baik yaitu sebanyak 61,11 \%, dapat ditarik kesimpulan bahwa secara umum supervisi pengawas satuan pendidikan pada SMA Ma'arif NU 5 Purbolinggo telah dilaksanakan secara cukup baik.

Data ini dapat diartikan bahwa pelaksanaan supervisi pengawas satuan pendidikan cukup sesuai dengan tugas dan fungsi, program, target, dan kompetensi supervisor pengawas. Para guru menilai bahwa supervisi pengawas cukup membantu pelaksanaan tugas-tugas mereka sebagai guru. Kriteria cukup baik dalam pelaksanaan supervisi pengawas ini masih dapat terus ditingkatkan dengan memperhatikan pada faktor-faktor yang dalam item pernyataan masih memperoleh skor yang rendah. Pelaksanaan supervisi pengawas yang baik diharapkan mampu mendorong kinerja guru yang pada akhirnya meningkatkan mutu proses pendidikan dan hasil pendidikan. 
Tabel 2. Penilaian Responden terhadap Pernyataan Kuesioner pada Variabel Supervisi Pengawas

\begin{tabular}{|c|c|c|c|c|}
\hline $\begin{array}{c}\text { PERNYATAA } \\
\mathbf{N}\end{array}$ & $\begin{array}{c}\text { SKO } \\
\text { R } \\
\text { REA } \\
\text { L }\end{array}$ & $\begin{array}{c}\text { SKO } \\
\text { R } \\
\text { MAK } \\
\text { S }\end{array}$ & $\%$ & $\begin{array}{c}\text { KRITERI } \\
\text { A }\end{array}$ \\
\hline $\begin{array}{l}\text { 1. Pengawas } \\
\text { Sekolah } \\
\text { membimbing } \\
\text { guru memilih } \\
\text { dan } \\
\text { menggunakan } \\
\text { strategi } \\
\text { pembelajaran }\end{array}$ & 70 & 108 & $\begin{array}{c}64,8 \\
1\end{array}$ & $\begin{array}{l}\text { Cukup } \\
\text { Baik }\end{array}$ \\
\hline $\begin{array}{l}\text { 2. Pengawas } \\
\text { Sekolah } \\
\text { membimbing } \\
\text { guru memilih } \\
\text { dan } \\
\text { menggunakan } \\
\text { metode } \\
\text { pembelajaran }\end{array}$ & 69 & 108 & $\begin{array}{c}63,8 \\
9\end{array}$ & $\begin{array}{l}\text { Cukup } \\
\text { Baik }\end{array}$ \\
\hline $\begin{array}{l}\text { 3. Pengawas } \\
\text { Sekolah } \\
\text { membimbing } \\
\text { guru memilih } \\
\text { dan } \\
\text { menggunakan } \\
\text { teknik } \\
\text { pembelajaran }\end{array}$ & 74 & 108 & $\begin{array}{c}68,5 \\
2\end{array}$ & Baik \\
\hline $\begin{array}{l}\text { 4. Pengawas } \\
\text { Sekolah } \\
\text { membimbing } \\
\text { guru } \\
\text { menyusun } \\
\text { silabus } \\
\text { pembelajaran }\end{array}$ & 73 & 108 & $\begin{array}{c}67,5 \\
9\end{array}$ & Baik \\
\hline $\begin{array}{l}\text { 5. Pengawas } \\
\text { Sekolah } \\
\text { membimbing } \\
\text { guru } \\
\text { menyusun } \\
\text { RPP } \\
\end{array}$ & 71 & 108 & $\begin{array}{c}65,7 \\
4\end{array}$ & $\begin{array}{c}\text { Cukup } \\
\text { Baik }\end{array}$ \\
\hline $\begin{array}{l}\text { 6. Pengawas } \\
\text { Sekolah } \\
\text { membimbing } \\
\text { guru dalam } \\
\text { pengembanga } \\
\text { n bahan ajar }\end{array}$ & 72 & 108 & $\begin{array}{c}66,6 \\
7\end{array}$ & Baik \\
\hline $\begin{array}{l}\text { 7. Pengawas } \\
\text { Sekolah } \\
\text { membimbing } \\
\text { guru dalam } \\
\text { proses } \\
\text { penilaian } \\
\text { hasil belajar } \\
\text { siswa }\end{array}$ & 70 & 108 & $\begin{array}{c}64,8 \\
1\end{array}$ & $\begin{array}{l}\text { Cukup } \\
\text { Baik }\end{array}$ \\
\hline $\begin{array}{l}\text { 8. Pengawas } \\
\text { Sekolah } \\
\text { membimbing } \\
\text { guru } \\
\text { membuat } \\
\text { analisis hasil } \\
\text { belajar siswa } \\
\end{array}$ & 66 & 108 & $\begin{array}{c}61,1 \\
1\end{array}$ & $\begin{array}{c}\text { Cukup } \\
\text { Baik }\end{array}$ \\
\hline $\begin{array}{l}\text { 9. Pengawas } \\
\text { Sekolah } \\
\text { membimbing } \\
\text { guru } \\
\text { membuat } \\
\text { database hasil } \\
\text { belajar siswa } \\
\end{array}$ & 73 & 108 & $\begin{array}{c}67,5 \\
9\end{array}$ & Baik \\
\hline 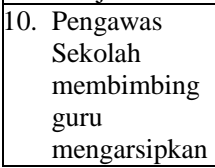 & 70 & 108 & $\begin{array}{c}64,8 \\
1\end{array}$ & $\begin{array}{l}\text { Cukup } \\
\text { Baik }\end{array}$ \\
\hline
\end{tabular}

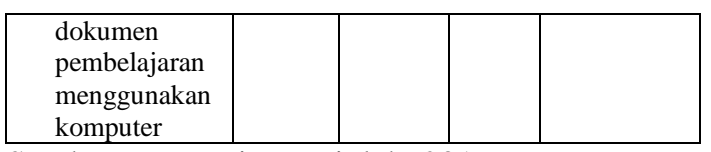

Sumber: Data Primer Diolah, 2016

Berdasarkan data di atas dapat dinyatakan bahwa faktor pengawas sekolah membimbing guru membuat analisis hasil belajar siswa, mendapat skor yang paling rendah dibanding faktor-faktor lainnya. Oleh karena itu diharapkan faktor ini perlu mendapat perhatian dari supervisor pengawas satuan pendidikan dengan melakukan upaya-upaya perbaikan. Pembimbingan guru oleh supervisor pengawas dalam melakukan analisis hasil belajar dapat dilakukan antara lain dengan cara pertemuan intensif baik secara bersama-sama maupun secara individual, sesuai dengan pedoman kerja supervisi pengawas. Dalam pertemuan pembinaan itu perlu dijelaskan konsep dan teori tentang analisis hasil belajar siswa dan cara melakukan analisis. Untuk lebih efektifnya pembimbingan dalam melakukan analisis hasil belajar dapat memanfaatkan teknologi informasi dan keterampilan menggunakan komputer.

\section{B. Analisis Kepemimpinan Kepala Sekolah (Variabel Bebas X2)}

Tabel 3. Distribusi Data Skor Kepemimpinan Kepala Sekolah

\begin{tabular}{|c|c|c|c|c|}
\hline No & Skor & Kategori & Frekuensi & $\%$ \\
\hline 1 & $\begin{array}{ll}22 & - \\
23 & \end{array}$ & Baik & 5 & 19,44 \\
\hline 2 & $\begin{array}{ll}20 & - \\
21 & \end{array}$ & $\begin{array}{l}\text { Cukup } \\
\text { Baik }\end{array}$ & 17 & 47,22 \\
\hline 3 & $\begin{array}{ll}18 & - \\
19 & \end{array}$ & $\begin{array}{l}\text { Kurang } \\
\text { Baik }\end{array}$ & 14 & 38,88 \\
\hline & & Jumlah & 36 & 100 \\
\hline
\end{tabular}

Sumber: Data Primer Diolah, 2016

Dari 36 responden penelitian, yang menyatakan bahwa kepemimpinan kepala sekolah telah dilaksanakan dengan Baik dinyatakan oleh 5 responden $(19,44 \%)$, yang menyatakan Cukup Baik ada 17 responden $(47,22 \%)$ yang menyatakan Kurang Baik ada 14 responden $(38,88 \%)$.

Dari hasil di atas, dominannya jawaban responden yang menyatakan bahwa kepemimpinan kepala sekolah termasuk dalam kategori Cukup Baik yaitu sebanyak 47,22 \%, dapat ditarik kesimpulan bahwa secara umum kepemimpinan kepala sekolah pada SMA Ma'arif NU 5 Purbolinggo telah dilaksanakan secara cukup baik.

Data ini dapat diartikan bahwa penerapan kepemimpinan oleh kepala sekolah cukup sesuai dengan kondisi dan harapan para guru. Para guru menilai bahwa kepemimpinan kepala sekolah cukup membantu pelaksanaan tugastugas guru dalam pembelajaran. Kepemimpinan kepala sekolah dinilai mampu menciptakan 
hubungan kerja yang harmonis dan efektif dalam mencapai tujuan pembelajaran. Kriteria cukup baik dalam pelaksanaan kepemimpinan kepala sekolah ini hendaknya ditingkatkan lagi di masa datang dengan memperhatikan pada faktor-faktor yang dalam item pernyataan masih memperoleh skor yang rendah. Kepemimpinan kepala sekolah yang baik, sesuai dengan kondisi sekolah dan harapan para guru diharapkan mampu mendorong kinerja guru lebih baik lagi. Upaya perbaikan di bidang kepemimpinan kepala sekolah yang dimaksudkan membantu peningkatan kinerja guru difokuskan pada mutu pendidikan.

Tabel 4. Penilaian Responden terhadap

Pernyataan Kuesioner pada Variabel Kepemimpinan Kepala Sekolah

\begin{tabular}{|c|c|c|c|c|}
\hline $\begin{array}{c}\text { PERNYATAA } \\
\mathbf{N}\end{array}$ & $\begin{array}{c}\text { SKO } \\
\text { R } \\
\text { REA } \\
\text { L }\end{array}$ & $\begin{array}{l}\text { SKO } \\
\text { R } \\
\text { MAK } \\
\text { S }\end{array}$ & $\%$ & $\begin{array}{c}\text { KRI } \\
\text { TER } \\
\text { IA }\end{array}$ \\
\hline 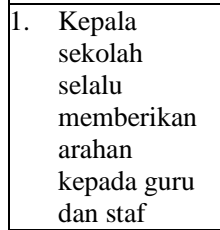 & 72 & 108 & $\begin{array}{c}66,6 \\
7\end{array}$ & Baik \\
\hline \begin{tabular}{|l} 
2. \\
Kepala \\
sekolah \\
selalu \\
membimbing \\
guru dan staf \\
dalam \\
melakukan \\
pekerjaan \\
\end{tabular} & 70 & 108 & $\begin{array}{c}64,8 \\
1\end{array}$ & $\begin{array}{l}\text { Cuku } \\
\mathrm{p} \\
\text { Baik }\end{array}$ \\
\hline 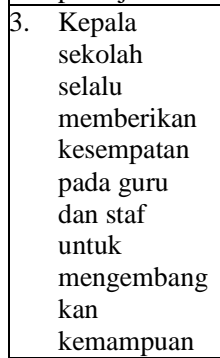 & 75 & 108 & $\begin{array}{c}69,4 \\
4\end{array}$ & Baik \\
\hline 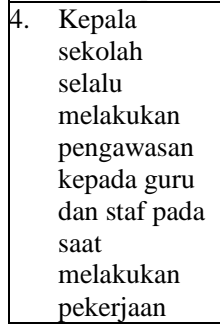 & 75 & 108 & $\begin{array}{c}69,4 \\
4\end{array}$ & Baik \\
\hline \begin{tabular}{|l} 
5. \\
Kepala \\
sekola \\
mempunyai \\
kemampuan \\
rata-rata di \\
atas guru dan \\
staf pada \\
bidang Iptek \\
\end{tabular} & 72 & 108 & $\begin{array}{c}66,6 \\
7\end{array}$ & Baik \\
\hline 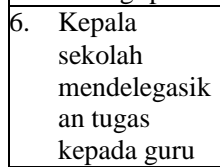 & 70 & 108 & $\begin{array}{c}64,8 \\
1\end{array}$ & $\begin{array}{c}\text { Cuku } \\
\mathrm{p} \\
\text { Baik }\end{array}$ \\
\hline $\begin{array}{|ll|}7 . & \text { Kepala } \\
& \text { sekolah } \\
& \text { mendelegasik } \\
\end{array}$ & 67 & 108 & $\begin{array}{c}62,0 \\
4\end{array}$ & $\begin{array}{c}\text { Cuku } \\
\mathrm{p} \\
\text { Baik }\end{array}$ \\
\hline
\end{tabular}

\begin{tabular}{|c|c|c|c|c|c|}
\hline & $\begin{array}{l}\text { an tugas } \\
\text { kepada guru }\end{array}$ & & & & \\
\hline 8. & $\begin{array}{l}\text { Kepala } \\
\text { sekolah } \\
\text { selalu } \\
\text { menanggapi } \\
\text { aspirasi dan } \\
\text { minat } \\
\text { bawahan } \\
\end{array}$ & 71 & 108 & $\begin{array}{c}65,7 \\
4\end{array}$ & $\begin{array}{c}\text { Cuku } \\
\mathrm{p} \\
\text { Baik }\end{array}$ \\
\hline & $\begin{array}{l}\text { Kepala } \\
\text { sekolah } \\
\text { mempunyai } \\
\text { kepedulian } \\
\text { yang tinggi } \\
\text { terhadap } \\
\text { bawahan }\end{array}$ & 67 & 108 & $\begin{array}{c}62,0 \\
4\end{array}$ & $\begin{array}{c}\text { Cuku } \\
\mathrm{p} \\
\text { Baik }\end{array}$ \\
\hline & $\begin{array}{l}\text { Kepala } \\
\text { sekolah } \\
\text { selalu } \\
\text { tanggap } \\
\text { terhadap } \\
\text { kebutuhan } \\
\text { bawahan }\end{array}$ & 74 & 108 & $\begin{array}{c}68,5 \\
2\end{array}$ & Baik \\
\hline
\end{tabular}

Sumber: Data Primer Diolah, 2016

Berdasarkan data di atas dapat dinyatakan bahwa faktor kepala sekolah dalam pelaksanaan tugas sehari-hari belum sepenuhnya memberikan delegasi tugas kepada guru, demikian juga dalam hal kepedulian terhadap keadaan para guru masih dinilai belum cukup. Dua faktor ini hendaknya menjadi perhatian khusus dalam upaya meningkatkan kepemimpinan kepala sekolah. Para guru akan merasa dilibatkan dan memiliki tanggung jawab apabila diberikan tugas dan kesenangan oleh kepala sekolah dalam melaksanakan tugas rutin maupun tugas-tugas yang sifatnya insidentil.

Meningkatnya delegasi tugas dari kepala sekolah kepada guru dan kepedulian kepala sekolah terhadap kondisi-kondisi guru dan staf sekolah diharapkan mampu memperbaiki kepemimpinan secara keseluruhan, sehingga akan dapat mendorong kinerja guru dalam tugas.

\section{Analisis Variabel Kinerja Guru (Variabel Terikat Y)}

Tabel 5. Distribusi Data Skor Kinerja Guru

\begin{tabular}{|c|c|c|c|c|}
\hline No & Skor & Kategori & Frekuensi & $\%$ \\
\hline 1 & $\begin{array}{ll}23 & - \\
24 & \end{array}$ & Baik & 7 & 19,44 \\
\hline 2 & $\begin{array}{ll}20 & - \\
22 & \end{array}$ & $\begin{array}{l}\text { Cukup } \\
\text { Baik }\end{array}$ & 21 & 58,33 \\
\hline 3 & $\begin{array}{ll}18 & - \\
19 & \\
\end{array}$ & $\begin{array}{l}\text { Kurang } \\
\text { Baik }\end{array}$ & 8 & 22,22 \\
\hline & & Jumlah & 36 & 100 \\
\hline
\end{tabular}

Sumber: Data Primer Diolah, 2016

Dari 36 responden penelitian, yang menyatakan bahwa kinerja guru menunjukkan pada kategori dengan Baik ada 7 responden $(19,44 \%)$, yang menyatakan Cukup Baik ada 21 responden $(58,33 \%)$ yang menyatakan Kurang Baik ada 8 responden $(22,22 \%)$.

Dari hasil di atas, dominannya jawaban responden yang menyatakan bahwa kinerja guru termasuk dalam kategori Cukup Baik yaitu 
sebanyak 58,33\%, dapat ditarik kesimpulan bahwa secara umum kinerja guru pada SMA Ma'arif NU 5 Purbolinggo dapat dikatakan sudah cukup baik cenderung baik. Data ini dapat diartikan bahwa kinerja guru dalam semua aspek yaitu prestasi, tanggung jawab, kerjasama dan prakarsa sudah menunjukkan kondisi yang cukup baik.

Adanya kinerja guru sebanyak 22,22\% yang berada kategori kurang baik, perlu mendapat perhatian dari kepala sekolah dan penyelenggara sekolah, untuk dilakukan perbaikan pada semua aspek kinerja guru yaitu prestasi, tanggung jawab, kerjasama, dan prakarsa, sehingga nantinya diharapkan kinerja guru secara keseluruhan akan berada pada kategori baik.

\section{Tabel 6. Penilaian Responden terhadap} Variabel Kinerja Guru

\begin{tabular}{|c|c|c|c|c|}
\hline PERNYATAAN & $\begin{array}{c}\text { SKO } \\
\text { R } \\
\text { REA } \\
\text { L } \\
\end{array}$ & $\begin{array}{c}\text { SKO } \\
\text { R } \\
\text { MA } \\
\text { KS } \\
\end{array}$ & $\%$ & $\begin{array}{c}\text { KRI } \\
\text { TRI } \\
\text { A }\end{array}$ \\
\hline $\begin{array}{l}\text { 1. Saya } \\
\text { memahami } \\
\text { tugas-tugas } \\
\text { sebagai } \\
\text { pendidik dan } \\
\text { pengajar } \\
\end{array}$ & 75 & 108 & $\begin{array}{l}69 \\
44\end{array}$ & Baik \\
\hline $\begin{array}{l}\text { 2. Saya } \\
\text { mempunyai } \\
\text { keterampilan } \\
\text { yang sangat } \\
\text { baik dalam } \\
\text { melaksanakan } \\
\text { tugas. } \\
\end{array}$ & 75 & 108 & $\begin{array}{l}69, \\
44\end{array}$ & Baik \\
\hline $\begin{array}{l}\text { 3. Saya selalu } \\
\text { berada di } \\
\text { tempat tugas } \\
\text { dalam segala } \\
\text { keadaan }\end{array}$ & 75 & 108 & $\begin{array}{l}69 \\
44\end{array}$ & Baik \\
\hline $\begin{array}{l}\text { 4. Saya tidak } \\
\text { pernah } \\
\text { melemparkan } \\
\text { kesalahan pada } \\
\text { orang lain }\end{array}$ & 72 & 108 & $\begin{array}{c}66 \\
67\end{array}$ & Baik \\
\hline $\begin{array}{l}\text { 5. Saya selalu } \\
\text { mentaati jam } \\
\text { kerja }\end{array}$ & 74 & 108 & $\begin{array}{l}68, \\
52\end{array}$ & Baik \\
\hline $\begin{array}{l}\text { 6. Saya selalu } \\
\text { mentaati } \\
\text { perintah } \\
\text { kedinasan } \\
\end{array}$ & 78 & 108 & $\begin{array}{l}72, \\
22\end{array}$ & Baik \\
\hline $\begin{array}{l}\text { 7. Dapat bekerja } \\
\text { sama dengan } \\
\text { pihak lain } \\
\text { dalam } \\
\text { melaksanakan } \\
\text { tugas } \\
\end{array}$ & 73 & 108 & $\begin{array}{l}67 \\
60\end{array}$ & Baik \\
\hline $\begin{array}{l}\text { 8. Saya dapat } \\
\text { menerima usul } \\
\text { orang lain }\end{array}$ & 77 & 108 & $\begin{array}{l}71 \\
30\end{array}$ & Baik \\
\hline $\begin{array}{l}\text { 9. Selalu ada } \\
\text { inisiatif dalam } \\
\text { melaksanakan } \\
\text { tugas }\end{array}$ & 79 & 108 & $\begin{array}{c}73 \\
15\end{array}$ & Baik \\
\hline $\begin{array}{l}10 . \quad \text { Menya } \\
\text { mpaikan } \\
\text { wawasan baru } \\
\text { dalam } \\
\text { pembelajaran. }\end{array}$ & 70 & 108 & $\begin{array}{l}64 \\
82\end{array}$ & $\begin{array}{l}\text { Cuku } \\
\mathrm{p} \\
\text { Baik }\end{array}$ \\
\hline
\end{tabular}

Sumber: Data Primer Diolah, 2016
Berdasarkan data di atas dapat dinyatakan bahwa faktor wawasan baru dalam diri guru masih perlu peningkatan, karena di antara semua pernyataan yang diajukan, faktor ini masih mendapat skor yang paling rendah. Selain itu juga dalam hal kesadaran diri, terutama pada saat ada hal yang kurang sesuai, masih ada kecenderungan melemparkan kesalahan atau tanggung jawab atas pekerjaan itu pada orang lain. Sedangkan faktor inisiatif dalam melaksanakan tugas pada guru sudah baik.

Dari data ini dapat dijelaskan bahwa pada sebagian guru masih belum menunjukkan kinerja terbaiknya, sehingga upaya perbaikan dan peningkatan kinerja guru akan lebih efektif apabila ditekankan dalam hal memperluas wawasan guru baik terkait dengan bidang keilmuan yang diajarkan maupun dalam hal metode pembelajaran.

Peningkatan kinerja guru juga akan lebih efektif dilakukan melalui upaya membangun kesadaran diri di kalangan guru untuk dapat bertanggung jawab atas setiap sikap dan tindakan guru baik dalam pembelajaran, pelaksanaan tugas-tugas, maupun dalam pergaulan sehari-hari di sekolah maupun di masyarakat.

Upaya peningkatan kinerja guru akan lebih efektif dan optimal apabila diperhatikan faktorfaktor supervisi pengawas satuan pendidikan dan kepemimpinan kepala sekolah. Hal ini karena kinerja guru memegang peranan yang penting dalam keberhasilan pendidikan di sekolah. Meningkatnya kinerja guru berarti meningkat pula mutu proses pembelajaran yang akhirnya akan meningkat pula mutu pendidikan.

\section{Analisis Kuantitatif}

\section{A. Koefisien Determinasi $(R$ Square $)$ Hipotesis Penelitian}

Koefisian determinasi (RSquare) untuk mengukur seberapa jauh kemampuan model dalam menerangkan variasi-variabel dependen. Nilai koefisien determinasi yang kecil berarti kemampuan variabel-variabel independen dalam menjelaskan variasi-variabel dependen sangat terbatas. Nilai koefisien determinasi yang mendekati 1 berarti variabel-variabel independen memberikan hampir semua informasi yang dibutuhkan untuk memprediksi variasi-variabel dependent.

\section{Tabel 7. Nilai Koefisien Determinasi Hipotesis Penelitian} Model Sunmarn

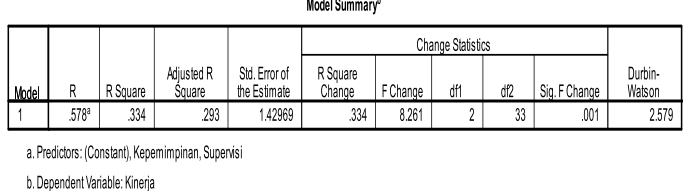

Dari Tabel 7 di atas dapat diketahui koefisien determinasi (RSquare) sebesar 0,334 
atau 34,4\%. Hasil tersebut memberikan pengertian bahwa variabel dependen sebesar $34,4 \%$ sedangkan sisanya sebesar $65,6 \%$ dijelaskan oleh variabel independen lainnya, yang tidak dimasukkan dalam model penelitian ini. Setelah paradigma variabel supervisi pengawas satuan pendidikan dan kepemimpinan kepala sekolah disesuaikan dengan menggunakan Adjusted $R$ Square, maka dapat dicapai hasil 0,293 yang menyatakan bahwa variabel kinerja dipengaruhi oleh variabel supervisi pengawas satuan pendidikan dan kepemimpinan kepala sekolah sebesar 29,3 $\%$.

\section{B. Pengujian Hipotesis Secara Simultan}

Untuk menguji pengaruh secara simultan variabel supervisi pengawas satuan pendidikan dan kepemimpinan kepala sekolah terhadap kinerja guru pada SMA Ma'arif NU 5 Purbolinggo dengan Uji Statistik F (Uji F) diperoleh hasil sebagai berikut ini.

\section{Tabel 8. Hasil Pengujian Hipotesis Secara} Simultan

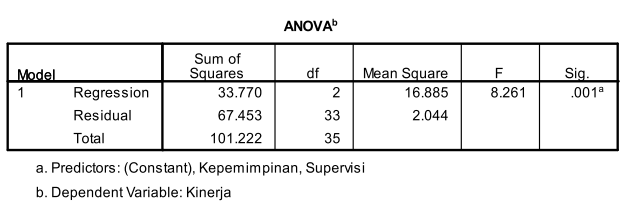

Dari Tabel 8. diketahui bahwa dengan nilai siginifikasi $0,001<0,05$ maka hipotesis ketiga; "Terdapat pengaruh yang signifikan supervisi pengawas satuan pendidikan dan kepemimpinan kepala sekolah secara bersamasama terhadap kinerja guru pada SMA Ma'arif NU 5 Purbolinggo" dapat diterima. Artinya secara serempak supervisi pengawas satuan pendidikan dan kepemimpinan kepala sekolah berpengaruh signifikan terhadap kinerja guru pada pada SMA Ma'arif NU 5 Purbolinggo.

\section{Pengujian Hipotesis Secara Parsial}

Tabel 9. Hasil Pengujian Hipotesis Secara Parsial

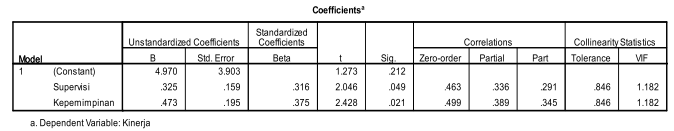

Berdasarkan hasil model regresi linier berganda yang diolah dengan menggunakan bantuan program komputer software SPSS versi 17.00, seperti Tabel 4.9. diatas, maka diperoleh hasil persamaan regresi sebagai berikut:

$$
\begin{aligned}
\mathrm{Y}= & 4,970+0,325 \mathrm{X}_{1}+0,473 \mathrm{X}_{2}+\mathrm{e} \\
\mathrm{Y}= & 4,970+0,325 \text { (supervise pengawas) }+ \\
& 0,473 \text { (kepemimpinan kepala sekolah) }+\mathrm{e}
\end{aligned}
$$

Dari data tersebut dapat dijelaskan bahwa:

1. Nilai signifikansi constanta 4,970 maka dapat disimpulkan bahwa pada saat diasumsikan tidak ada pengaruh supervisi pengawas satuan pendidikan dan kepemimpinan kepala sekolah, maka kinerja guru sesuai constanta pada persamaan regresi tersebut.

2. Nilai signifikansi variabel supervisi pengawas satuan pendidikan (X1) sebesar $0,049<0,05$ maka dapat disimpulkan bahwa hipotesis pertama; "Terdapat pengaruh yang signifikan supervisi pengawas satuan pendidikan terhadap kinerja guru." dapat diterima.

3. Nilai signifikansi variabel kepemimpinan kepala sekolah (X2) yang bernilai 0,021> 0,05 maka dapat disimpulkan bahwa hipotesis kedua; "Terdapat pengaruh yang signifikan kepemimpinan kepala sekolah terhadap kinerja guru." dapat diterima.

Berdasarkan uji hipotesis secara parsial di atas maka dapat disimpulkan bahwa kinerja guru sangat kuat dipengaruhi oleh kedua variabel, supervise pengawas satuan pendidikan dan kepemimpinan kepala sekolah. Pengaruh kepemimpinan kepala sekolah relatif lebih kuat dibandingkan pengaruh supervise pengawas satuan pendidikan.

Berdasarkan data penelitian ini maka untuk menunjang peningkatan kinerja guru, perlu dilakukan upaya-upaya lebih optimal dalam supervisi pengawas satuan pendidikan dan kepemimpinan kepala sekolah, mengingat bahwa kontribusi kedua variabel yang diteliti secara simultan memberikan kontribusi sebesar $34,4 \%$ terhadap kinerja guru.

Kepemimpinan yang baik dapat memberikan teladan dan ketegasan dan supervisi yang lebih menitikberatkan pada aspek akademik dan keterampilan teknis bagi guru untuk melaksanakan tugas dengan baik yang akan dapat meningkatkan kinerja guru.

\section{PENUTUP}

\section{1) Kesimpulan}

Kesimpulan dari penelitian ini adalah sebagai berikut:

1. Terdapat pengaruh yang signifikan supervisi pengawas satuan pendidikan terhadap kinerja guru pada SMA Ma'arif NU 5 Purbolinggo, Kabupaten Lampung Timur.

2. Terdapat pengaruh yang signifikan kepemimpinan kepala sekolah terhadap kinerja guru.

3. Terdapat pengaruh yang signifikan supervisi pengawas satuan pendidikan dan kepemimpinan kepala sekolah secara bersama-sama terhadap kinerja guru.

\section{2) Saran}

Berdasarkan penelitian ini, penulis memberikan saran bahwa penelitian ini masih perlu untuk diteruskan dan dikembangkan lagi dengan cara menambahkan variabel yang lebih variatif lagi. 


\section{DAFTAR PUSTAKA}

Masaong, H. Abd. Kadim, 2012. Supervisi Pembelajaran dan Pengembangan Kapasitas Guru, Bandung: Alfabeta.

Nawawi, Hadari, 2003, Manajemen Sumber Daya Manusia untuk Bisnis yang Kompetitif, Gadjah Mada University Press, Yogyakarta.

Usman, Moh. Uzer, 2005. Menjadi Guru Profesional, Bandung: Remadja Rosdakarya

Peraturan Perundang-undangan Standar

Peraturan Pemerintah Nomor 32 Tahun 2013 tentang Perubahan atas Peraturan

Pemerintah Nomor 19 Tahun 2005 tentang Standar Nasional Pendidikan.

Peraturan Menteri Pendidikan Nasional Nomor 12 Tahun 2007 tentang Standar Pengawas Sekolah/Madrasah.

Peraturan Menteri Pendidikan Nasional Nomor 13 Tahun 2007 tentang Standar Kepala Sekolah/Madrasah.

Peraturan Menteri Pendidikan Nasional Nomor 16 Tahun 2007 tentang Standar Kualifikasi Akademik dan Kompetensi Guru. 